\title{
ON THE TREATMENT OF DISCONTINUITIES IN BEAM DEFLECTION PROBLEMS*
}

By B. S. CAIN (General Electric Company, Erie, Pa.)

In Mr. C. L. Brown's note on the treatment of discontinuities in beam deflection problems (Quarterly of Applied Mathematics, 1, 349-351), the last term of Eq. (7) is written in the form

$$
-P H_{a}(x-b) .
$$

Before Eq. (4) can be applied, however, this term must be put in the form

$$
-P H_{a}(x-a)-P H_{a}(a-b) \text {. }
$$

This allows Eq. (7) to be written in the form

$$
E I_{1} \frac{d^{2} y}{d x^{2}}=\frac{P x}{2}-P H_{b}(x-b)-\frac{P}{2} H_{a}(x-a)+\frac{P}{2}(2 b-a) H_{a}
$$

and gives, in place of Eq. (8),

$$
E I_{1} y=\frac{P x^{3}}{12}-P H_{b} \frac{(x-b)^{3}}{6}-\frac{P}{2} H_{a} \frac{(x-a)^{3}}{6}+\frac{P}{2}(2 b-a) H_{a} \frac{(x-a)^{2}}{2}+C_{1} x+C_{2} \text {. }
$$

Then

$$
C_{1}=-\frac{P}{12 b}\left[3 b^{3}+(2 b-a)^{3}\right], \quad C_{2}=0
$$

\footnotetext{
* Received July 12, 1944.
} 